\title{
Neuronal Cell Death Is Preceded by Cell Cycle Events at All Stages of Alzheimer's Disease
}

\author{
Yan Yang, ${ }^{1}$ Elliott J. Mufson, ${ }^{2}$ and Karl Herrup ${ }^{1}$ \\ ${ }^{1}$ Alzheimer Research Laboratory, University Hospitals of Cleveland and Department of Neurosciences, Case Western Reserve University, School of \\ Medicine, Cleveland, Ohio 44106, and 'Department of Neurological Sciences and Alzheimer's Disease Center, Rush Presbyterian Medical Center, Chicago, \\ Illinois 60612
}

Cell cycle events play a major role in the loss of neurons in advanced Alzheimer's disease (AD). It is currently unknown, however, whether the same is true for the neuronal losses in early disease stages. To explore this issue we analyzed brain autopsy material from individuals clinically categorized with mild cognitive impairment (MCI), many if not most of whom will progress to AD. Immunocytochemistry for three cell cycle-related proteins, proliferating cell nuclear antigen, cyclin D, and cyclin B, was performed on sections from hippocampus, basal nucleus of Meynert, and entorhinal cortex. The results obtained from MCI cases were compared with material from individuals diagnosed with $\mathrm{AD}$ and those without cognitive impairment. In both hippocampus and basal nucleus, there was a significant percentage of cell cycle immunopositive neurons in the MCI cases. These percentages were similar to those found in the AD cases but significantly higher than non-cognitively impaired controls. In entorhinal cortex, the density of cell cycle-positive neurons was greater in MCI than in AD. However, we observed large variations in the percentages of immunopositive neurons from individual to individual. These findings lend support to the hypothesis that both the mechanism of cell loss (a cell cycle-induced death) and the rate of cell loss (a slow atrophy over several months) are identical at all stages of the AD disease process. The implication of the findings for human clinical trials is discussed.

Key words: PCNA; cyclin D; cyclin B; mild cognitive impairment; $\beta$-amyloid; tangles

\section{Introduction}

Mild cognitive impairment (MCI) is a term used to describe a subtle age-associated decline of human mental ability. It refers to a cognitive state in which minor problems with memory and complex mental tasks become clinically significant although the individual may still function well in his or her daily routine. The exact prognosis of individuals with MCI is not certain, but several studies have shown that a high percentage of them will progress to Alzheimer's disease (AD) within 3-5 years of diagnosis [for recent analysis, see Bennett et al. (2002)]. Although the idea of a

Received 0ct. 29, 2002; revised Jan. 7, 2003; accepted Jan. 10, 2003.

This work was supported by a gift from the Blanchette Hooker Rockefeller Fund, by grants from the National Institute on Aging (AG08012) and the National Institute of Neurological Diseases and Stroke (NS20591) to K.H. and Y.Y., and by grants from the National Institute of Aging (AG14449, A16668, A 09446, and AG10161) to E.J.M. We are indebted to the altruism and support of the hundreds of nuns, priests, and brothers from the following groups participating in the Religious Orders Study: Archdiocesan Priests of Chicago, Dubuque, and Milwaukee; Benedictine Monks, Lisle, IL, and Collegeville, MN; Benedictine Sisters of Erie, Erie, PA; Benedictine Sisters of the Sacred Heart, Lisle, IL; Capuchins, Appleton, Wl; Christian Brothers, Chicago, IL, and Memphis, TN; Diocesan priests of Gary, IN; Dominicans, River Forest, IL; Felician Sisters, Chicago, IL; Franciscan Handmaids of Mary, New York, NY; Franciscans, Chicago, IL; Holy Spirit Missionary Sisters, Techny, IL; Maryknolls, Los Altos, CA, and Maryknoll, NY; Norbertines, DePere, Wl; Oblate Sisters of Providence, Baltimore, MD; Passionists, Chicago, IL; Presentation Sisters, Dubuque, IA Servites, Chicago, IL; Sinsinawa Dominican Sisters, Chicago, IL, and Sinsinawa, Wl; Sisters of Charity, B.V.M., Chicago, IL, and Dubuque, IA; Sisters of the Holy Family, New Orleans, LA; Sisters of the Holy Family of Nazareth, Des Plaines, IL; Sisters of Mercy of the Americas, Chicago, IL, Aurora, IL, and Erie PA; Sisters of St. Benedict, St. Cloud and St. Joseph, MN; Sisters of St. Casimir, Chicago, IL; Sisters of St. Francis of Mary Immaculate, Joliet, IL; Sisters of St. Joseph of LaGrange, LaGrange Park, IL; Society of Divine Word, Techny, IL; Trappists, Gethsemane, KY, and Peosta, IA; and Wheaton Franciscan Sisters, Wheaton, IL. We also are indebted to the dedication and hard work of Julie Bach, Religious Orders Study Coordinator, Beth Howard, Wayne Longman, and Sabeena Shafaq of the Rush Brain Bank, and Greg Klein, WenQing Fan, and Joanne Wu for data retrieval. We thank Drs. D. Bennett and E. Cochran, heads of the Religious Orders Study Clinical and Neuropathology Cores, respectively.

Correspondence should be addressed to Dr. Yan Yang, Alzheimer Research Laboratory, University Hospitals of Cleveland and Department of Neurosciences, Case Western Reserve University, School of Medicine (E504), 10900 Euclid Avenue, Cleveland, 0H 44106. E-mail: yxy33@po.cwru.edu.

Copyright $\odot 2003$ Society for Neuroscience $\quad 0270-6474 / 03 / 232557-07 \$ 15.00 / 0$ strict linear progression is still debated, many researchers view MCI as a prodromal stage of AD (Petersen, 2000a,b; Morris et al., 2001).

In MCI, as in many other conditions that involve loss of neuronal function, there is pathological evidence of cell loss that accompanies the mental decline (Gomez-Isla et al., 1996; Mufson et al., 2000, 2002; Kordower et al., 2001). This raises an important question: if MCI represents a prodromal stage of $\mathrm{AD}$ and is accompanied by cell loss, what causes this first cohort of neurons to die? A clue to the answer comes from the persistent correlation of tau pathology and the resulting neurofibrillary tangles (NFTs) with the extent of dementia and cell loss (Mitchell et al., 2002; Rossler et al., 2002). One source for tau hyperphosphorylation is believed to be the deregulation of cell-cycle kinases, in particular Cdc2 (Vincent et al., 1996, 1997). Indeed, in end-stage AD, a number of laboratories have documented a correlation between nerve cell loss and the appearance of cell cycle-related proteins (Baumann et al., 1993; Lew and Wang, 1995; Arendt et al., 1996, 1998; Vincent et al., 1996, 1997; McShea et al., 1997; Nagy et al., 1997; Busser et al., 1998; Hoozemans et al., 2002). These proteins are not simply mis-expressed; rather they must work coordinately because the genomic DNA can be shown to be nearly completely replicated (Yang et al., 2001). We have shown that the percentage of these "cycling" neurons ranges from an average of $4 \%$ in fluorescent in situ hybridization preparations (Yang et al., 2001) to $9 \%$ in immunostained material (Busser et al., 1998). These are relatively high percentages because, if cell death were rapid, very few dying cells would be visible at any one moment $(\sim 0.01 \%)$. We propose that these percentages are evidence that the rate of cell death after cell cycle reentry must be slow, requiring months to complete (Busser et al., 1998; Yang et al., 2001). 
Table 1. Demographic and neuropathological characteristics

\begin{tabular}{lllll}
\hline & \multicolumn{4}{l}{ Clinical diagnosis } \\
\cline { 3 - 5 } & & MCI & AD & CO \\
& & $(n=10)$ & $(n=9)$ & $(n=6)$ \\
\hline Source & & Rush & Rush & CWRU \\
Age at death & Mean \pm SD & $85.3 \pm 5.87$ & $86 \pm 5.52$ & $73.5 \pm 5.72$ \\
PMI & Mean \pm SD & $4.73 \pm 1.89$ & $5.02 \pm 2.13$ & $14 \pm 4.60$ \\
\% of males & & $50 \%$ & $29 \%$ & $20 \%$ \\
MMSE & Mean \pm SD & $27.7 \pm 1.56$ & $18.2 \pm 7.7$ & N/A \\
Distribution of & & & & \\
\multicolumn{1}{c}{ Braak scores } & 0 & 0 & 0 & N/A \\
& I-II & 1 & 0 & N/A \\
& III-IV & 8 & 4 & N/A \\
Pathological & V-VI & 1 & 5 & N/A \\
Reagen diagnosis & & & & \\
& N0 & 0 & 0 & N/A \\
& Low & 3 & 1 & N/A \\
& Intermediate & 7 & 4 & N/A \\
& High & 0 & 4 & N/A \\
\hline
\end{tabular}

In the current work we show with immunocytochemistry of MCI autopsy material that the percentage of neurons engaged in a lethal cell cycle early in the disease process is similar to that found in individuals who die with frank AD. The implication of these findings from the standpoint of disease mechanisms and the conduct of human clinical trials is discussed.

\section{Materials and Methods}

Subjects. Human autopsy brain tissue was obtained from the two National Institute on Aging-funded AD centers. Brain tissue was routinely Formalin fixed, paraffin embedded, and sectioned at $10 \mu \mathrm{m}$. Tissue from all MCI and AD cases were obtained from the Religious Orders Study of the Rush Alzheimer's Disease Center (Chicago, IL). All MCI and AD cases were confirmed both clinically and pathologically as described previously (Gilmor et al., 1999; Mufson et al., 1999, 2000, 2002; Bennett et al., 2002; Mitchell et al., 2002). Mini-mental status examination (MMSE) scores were obtained for all cases (Table 1); the scores ranged from 25 to $30(27.7 \pm 1.89)$ for $\mathrm{MCI}$ and 3 to $25(18.2 \pm 7.7)$ for $\mathrm{AD}$. The average postmortem interval was of $\sim 5 \mathrm{hr}(5.02 \pm 2.13)$ for $\mathrm{AD}$ and $4.7 \mathrm{hr}$ $(4.73 \pm 1.89)$ for MCI tissue, ranging from 2 to $9 \mathrm{hr}$ (Table 1$)$. The six age-matched cognitively intact controls were obtained from the Memory and Aging Center, University Hospitals and Case Western Reserve University. Control brains were Formalin fixed, embedded in paraffin, and sectioned at $10 \mu \mathrm{m}$.

Immunocytochemistry. The proliferating cell nuclear antigen (PCNA) mouse monoclonal antibody recognizes the PCNA p36 protein (SC-56; Santa Cruz Biotechnology, Santa Cruz, CA) and was diluted 1:100 before use. The cyclin D mouse monoclonal antibody (SC-246; Santa Cruz Biotechnology) was raised against human cyclin D1 (p34) and used at a 1:100 dilution. The cyclin B1 mouse monoclonal IgG2b (Upstate Biotechnology, Lake Placid, NY) was also raised against the human protein and applied at a dilution of 1:50. A monoclonal mouse antibody, $6 \mathrm{E} 10$ (Signet, MA) was diluted 1:1000 and used to detect $\beta$-amyloid deposits. Paired helical filaments and neurofibrillary tangles were detected by a mouse monoclonal antibody against hypophosphorylated tau, AT-8 (Autogen-Bioclear, UK). This antibody was used at a 1:400 dilution.

All sections were deparaffinized in xylene and rehydrated through graded ethanol to water. The sections were soaked in $0.3 \%$ hydrogen peroxide in methanol for $20 \mathrm{~min}$ to remove endogenous peroxidase activity, rinsed in Tris-buffered saline (TBS), and pretreated in a solution of $0.1 \mathrm{M}$ citrate buffer heated to $90-95^{\circ} \mathrm{C}$ for $10 \mathrm{~min}$. Sections were cooled and rinsed in TBS. Slides were incubated in a blocking solution consisting of $0.1 \%$ blocking reagent (Boehringer Mannheim, Mannheim, Germany) and $10 \%$ goat serum in PBS at room temperature for $1 \mathrm{hr}$. After overnight incubation with the primary antibody $\left(4^{\circ} \mathrm{C}\right)$, the sections were washed three times in TBS before applying the secondary antibody, which was diluted in blocking solution at 1:200. The secondary antibody
Table 2. Percentage of immunopositive neurons (all sections/all cases)

\begin{tabular}{lll}
\hline & Cyclin D (\%) & PCNA (\%) \\
\hline MCI & 5.2 & 7.0 \\
Alzheimer's disease & 6.3 & 7.1 \\
Control & 0.4 & 0.4 \\
\hline
\end{tabular}

was left on the section for $1 \mathrm{hr}$ at room temperature; afterward, sections were rinsed in TBS. Rinsed sections were then incubated in Vectastain $\mathrm{ABC}$ Elite reagent for $1 \mathrm{hr}$, followed by three successive washes. The sections were then incubated in diaminobenzidine (DAB) as a substrate for visualization of the chromagen, according to the manufacturer's specification (Vector Peroxidase Substrate DAB kit; Vector Laboratories, Burlingame, CA). Some sections were counterstained with hematoxylin to aid in cell count studies, and all sections were covered with Permount. Immunohistochemical control sections (data not shown) were put through the identical staining procedure except for the omission of the primary antibody.

Cell counts. In hippocampus, all of the pyramidal neurons in the CA1CA4 fields of single sections were counted by profile counting methods (Guillery and Herrup, 1997) in material from MCI, AD, and control. A cell was scored only if it contained a clear, visible nucleus. The total number of immunopositive cells was also counted within all subfields of the hippocampus. The cell cycle-immunoreactive cells were counted only where the immunostaining was above background staining seen in other regions of the same section. To determine the percentage of positive cells in the hippocampus, the counts of immunopositive cells were divided by the total pyramidal cell count. For each case a minimum of 300 total cells was counted in a single section for each antibody examined (Table 2). The results are presented as a percentage of neurons rather than absolute numbers; thus no correction factors were deemed necessary. An investigator who was blinded to the condition of the sample performed all analysis.

\section{Results}

Although the clinical and neurological status of the MCI cases examined was similar and relatively uncompromised, the degree of Alzheimer-related pathology in their brains differed significantly. The pathologically least impacted MCI cases displayed

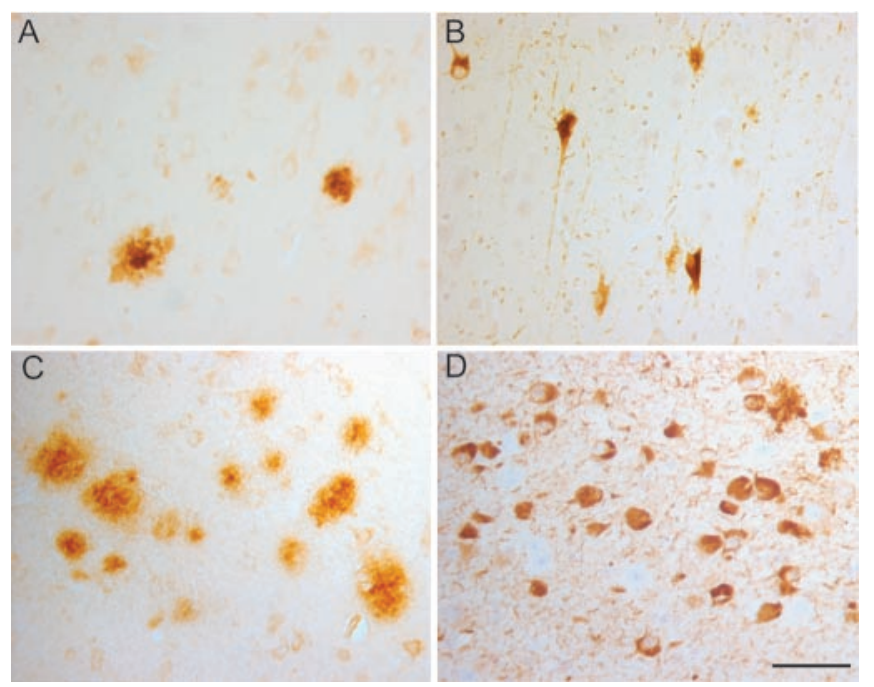

Figure 1. Histopathology of the hippocampus varies among the different $\mathrm{MCl}$ cases. In the hippocampus of the mildest $\mathrm{MCl}$ case, the $6 \mathrm{E} 11$ antibody recognizes only an occasional $\beta$-amyloid plaque $(A)$. Similarly, the mouse monoclonal AT- 8 antibody that recognizes phosphorylated tau protein detects relatively few tangle-bearing neurons $(B)$. In other $\mathrm{MCl}$ cases the extent of pathology was more significant. In some cases the level of 6E11-positive plaques ( $C$ and AT-8-positive tangles $(D)$ approached levels that might be expected in advanced Alzheimer's disease. Scale bar, $25 \mu \mathrm{m}$. 


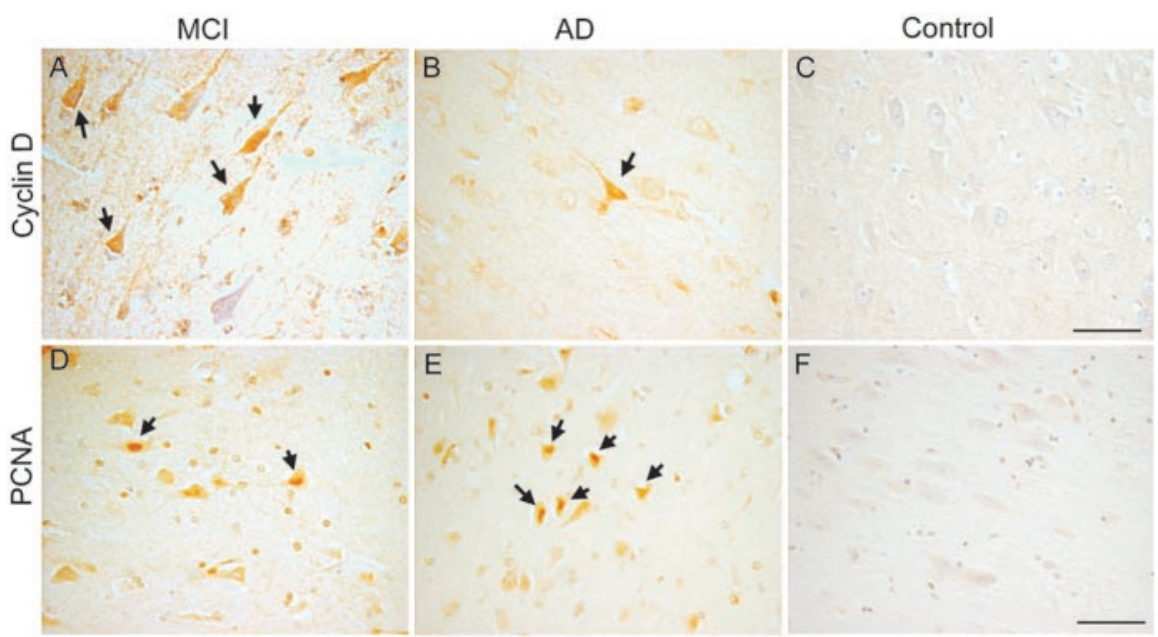

Figure 2. Immunocytochemistry reveals the expression of various cell cycle proteins in pyramidal neurons of the hippocampus. In both $\mathrm{MCI}(A)$ and $\mathrm{AD}(B)$, immunostaining for cyclin D reveals that a fraction of the hippocampal pyramidal cells express proteins that are normally found only in actively dividing cells. In contrast, age-matched controls ( $C$ show little if any evidence for cyclin D expression. A second mitotic marker, the DNA polymerase subunit PCNA, is also found in neurons of the hippocampus in $\mathrm{MCl}$ cases $(D)$ as well as in material from subjects who died with mild to moderate $A D(E)$. Little evidence for reexpression of PCNA is detected in control material ( F). Arrows indicate neurons stained positive for the two cell cycle markers. Scale bars, $25 \mu \mathrm{m}$.
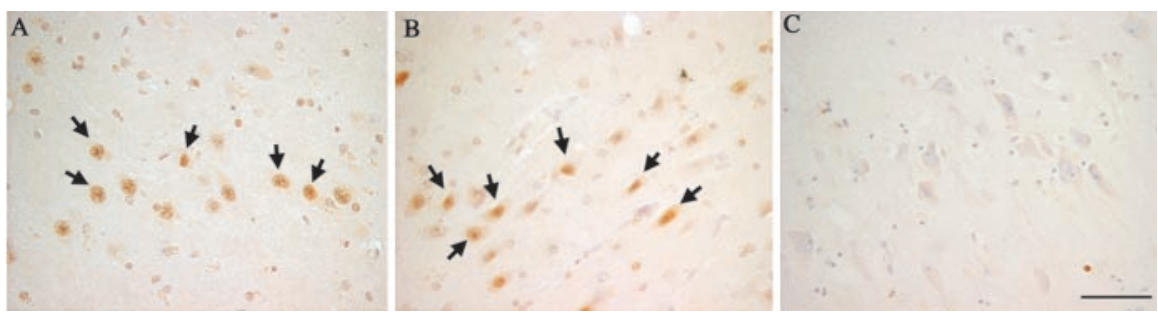

Figure 3. Hippocampal pyramidal cells stained for the cell cycle marker cyclin B1. Cells shown are from $M C l(A), A D(B)$, and a representative field from a normal, nondemented individual ( $($ ); the latter illustrates the lack of cyclin B1 staining. Arrows point to the cyclin B1-positive neurons in MCl and AD. Scale bar, $25 \mu \mathrm{m}$.

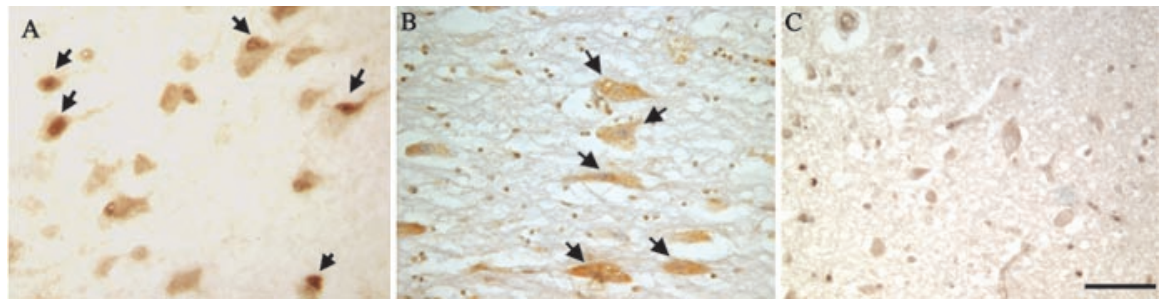

Figure 4. Nucleus basalis of Meynert immunostained for the cell cycle marker PCNA. In this second region where substantial neurodegeneration is known to occur in Alzheimer's disease, there is significant evidence for ectopic expression of cell cycle proteins in neurons that should be permanently postmitotic. Regions shown are from a representative $\mathrm{MCl}$ case $(A)$, an $A D$ case $(B)$, and an age-matched control (C). Arrows indicate immunopositive cells. Scale bar, $25 \mu \mathrm{m}$.

minor accumulations of $\beta$-amyloid plaque deposits and NFTs (Fig. 1A,B). The more pathologically involved MCI cases were heavily invested with plaques and NFTs (Fig. 1C,D). The AD cases displayed extensive plaque and tangle pathology in the hippocampus (data not shown). Their clinical and pathological diagnoses are summarized in Table 1.

\section{Hippocampus: cell cycle immunostaining}

Our most detailed analysis was performed on the large pyramidal neurons of the hippocampus. Sections were first stained with antibodies to cyclin $\mathrm{D}$, a Cdk4 regulatory subunit that is expressed as cells leave the $G_{0}$ phase of the cell cycle, pass the re- striction point, and proceed through the end of $\mathrm{G}_{1}$ (Baldin et al., 1993). Immunohistochemical processing revealed significant numbers of cyclin D-expressing neurons in $\mathrm{MCI}$ and $\mathrm{AD}$ (Fig. $2 A-C$ ). The number of these cells is near zero in the cognitively nonimpaired age-matched subjects (Fig. 2C). As a marker of S-phase, we used the PCNA antigen. The epitope recognized by the PCNA antibody resides on a subunit of the DNA polymerase holoenzyme, which is elevated primarily during S-phase (Prosperi, 1997). PCNA-immunopositive cells were easily visualized in both our $\mathrm{MCI}$ and $\mathrm{AD}$ subjects (Fig. 2D,E). Finally, as a marker of the $\mathrm{G}_{2}$-phase of the cell cycle, we stained additional sections with antibodies to cyclin $\mathrm{B}$, the regulatory subunit of the Cdc2 kinase. This marker also showed comparable levels of staining in both MCI and AD (Fig. $3 A, B$ ) but not in controls (Fig. 3C). In this study, as in previous work, there was no evidence of any neuron proceeding into M-phase. Condensed chromosomes were not seen in any neuronal nucleus, nor was there any evidence for the formation of a spindle apparatus.

\section{Nucleus basalis: cell cycle immunostaining}

The pyramidal cells of the hippocampus are not the only neurons to die during the progress of $\mathrm{AD}$. Adrenergic and serotonergic neurons of the brain stem are lost (Zweig et al., 1988) as are the large cholinergic neurons of the nucleus basalis of Meynert (Whitehouse et al., 1982). At late stages of $\mathrm{AD}$, we have shown previously that each of these neuronal populations has significant numbers of neurons that show evidence of having entered a cell cycle (Busser et al., 1998; Yang et al., 2001). We wished to determine whether in MCI the cycle-induced loss of cells was restricted to the hippocampus. Therefore, we examined the neurons of the nucleus basalis. Figure 4 shows that despite the higher overall density of cells, the basal nucleus neurons have significant cell cycle involvement in MCI cases (Fig. 4A); indeed, the levels of involvement are quite similar to those found in $\mathrm{AD}$ (Fig. 4B). As in hippocampus, nondemented age-matched controls show little or no evidence of cell cycle activity (Fig. 4C).

\section{Entorhinal cortex: cell cycle immunostaining}

Various evidence has suggested that the earliest neurodegenerative changes that accompany the progression of $\mathrm{AD}$ can be found in the entorhinal cortex. This is evident both in the extent of neuronal loss and in the appearance of neurofibrillary tangles (Hyman et al., 1984, 1986; Arnold et al., 1991; Braak and Braak, 1991; Price et al., 1991; Kordower et al., 2001; Mitchell et al., 2002). To compare the timing of appearance of cell cycle enzymes 
with these structural markers, we examined the presence of PCNA, cyclin D, and cyclin B in the entorhinal cortex. The present findings are consistent with previous analyses of the distribution of NFTs. The MCI cases currently examined showed early involvement of the large neurons of entorhinal cortex, specifically layers II, III, and V (Fig. 5A-C). Cell cycle markers were a prominent feature of the cells in these layers in all MCI cases examined; control tissue showed few or no immunopositive neurons (Fig. 5F). There were also substantial numbers of neurons that were strongly positive for cell cycle markers in the $\mathrm{AD}$ material (data not shown). Significantly, the incidence of neurons expressing such markers dropped to near zero at the boundary between entorhinal cortex and the adjacent temporal neocortex.

Of note is the fact that there was substantial variability in the density of cell cycle-positive neurons from one case to the next. For example, the density of PCNA-positive cells was found to range from large clusters of cell cycle-positive cells (Fig. $5 D)$ to a few isolated cells in a region of immunonegative neurons (Fig. 5E). These differences are real and representative of each case, because we found that the different cell cycle markers each gave comparable results if applied to nearby sections (data not shown). Because access to the MCI tissue is limited, it was not possible to determine whether this variability was caused by regional variations within a single individual or by global differences in cell cycle involvement among the different cases. Others have seen similarly large ranges of pathological involvement in MCI (Mitchell et al., 2002).

The similarity of these findings to those reported previously for neurofibrillary pathology raises the question of whether the location and density of the cell cycle changes that we observe bear a relationship to the presence of neurofibrillary changes. We stained sections from the same region as those used for the cell cycle studies with the AT-8 monoclonal antibody that recognizes phosphorylated tau protein. We performed this analysis on 10 MCI cases in which we had observed cell cycle changes. In every case, the regions that showed the highest levels of reactivity for cell cycle proteins (Fig. $6 B, D$ ) were the same regions that (by AT- 8 antigen) were the highest in hyperphosphorylated tau (Fig. $6 A, C)$. This spatial correlation supports our contention that the cell cycle changes observed are related to the neurodegenerative events.

\section{Cell counts}

The presence of cell cycle-positive neurons in MCI temporal cortex and the correlation between the location of these cells and other observed $\mathrm{AD}$ pathologies is strong evidence for the early involvement of cell cycle events in the neuronal death that occurs during the progression to $\mathrm{AD}$. To obtain a more precise comparison between the situations in $\mathrm{MCI}$ and $\mathrm{AD}$, we determined the percentages of immunopositive neurons in the hippocampal region containing cell cycle markers. As shown in Figure 7 , the percentages of cell cycle-positive neurons were similar in $\mathrm{AD}$ and MCI (Fig. $7 B, D$ ). This is in contrast with the considerably lower percentage of immunopositive cells seen in the nondemented

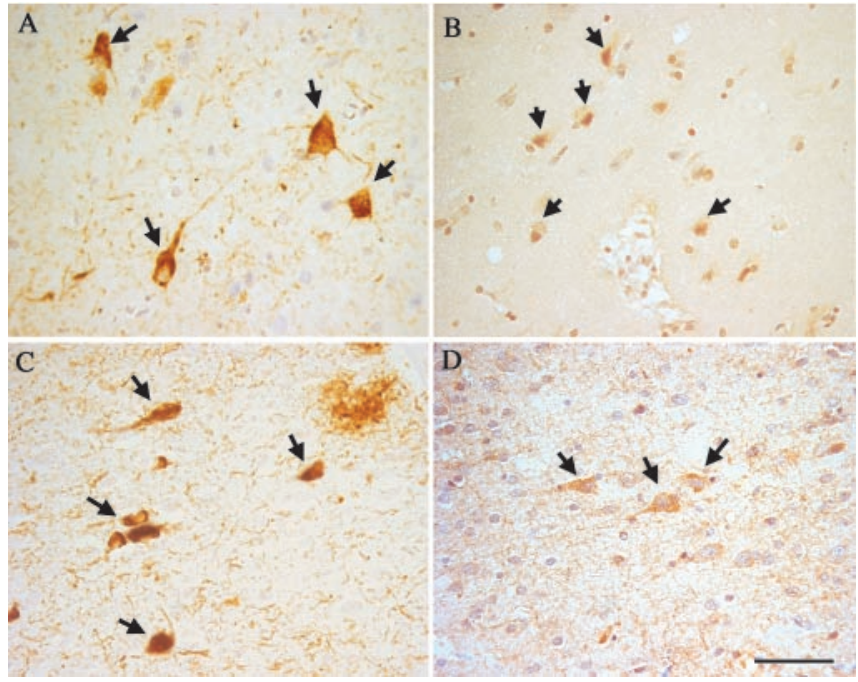

Figure 6. Spatial association of hyperphosphorylated tau protein and cell cycle markers in the MCl entorhinal cortex. In this series of near-neighbor sections, the monoclonal AT-8 antibody reveals the location of hyperphosphorylated tau protein in intraneuronal tangles in layer $\mathrm{V}$ $(A)$ and layer II ( $C$. In nearby sections, immunostaining for cyclin $B 1(B)$ and cyclin $D(D)$ shows that the cell cycle-positive neurons are closely associated with these NFT-bearing neurons. Scale bar, $25 \mu \mathrm{m}$.

controls. To achieve a higher level of detail, we tabulated each of the CA regions separately. This exercise is likely to contain a certain level of imprecision, because we had a single series of sections from each case and the anatomical location of our section sample varied from case to case. The representation of the individual CA fields was not uniform, and thus regional variability might well distort our numbers in any one sample. Despite these caveats, there appear to be few differences among the percentages of immunopositive neurons in the CA fields of either $\mathrm{AD}$ cases or MCI. One consistent exception is a higher level of cell cycle involvement in area CA1 (Fig. $7 A, C$ ). These differences are modest, and additional counts would be needed to verify their significance. 

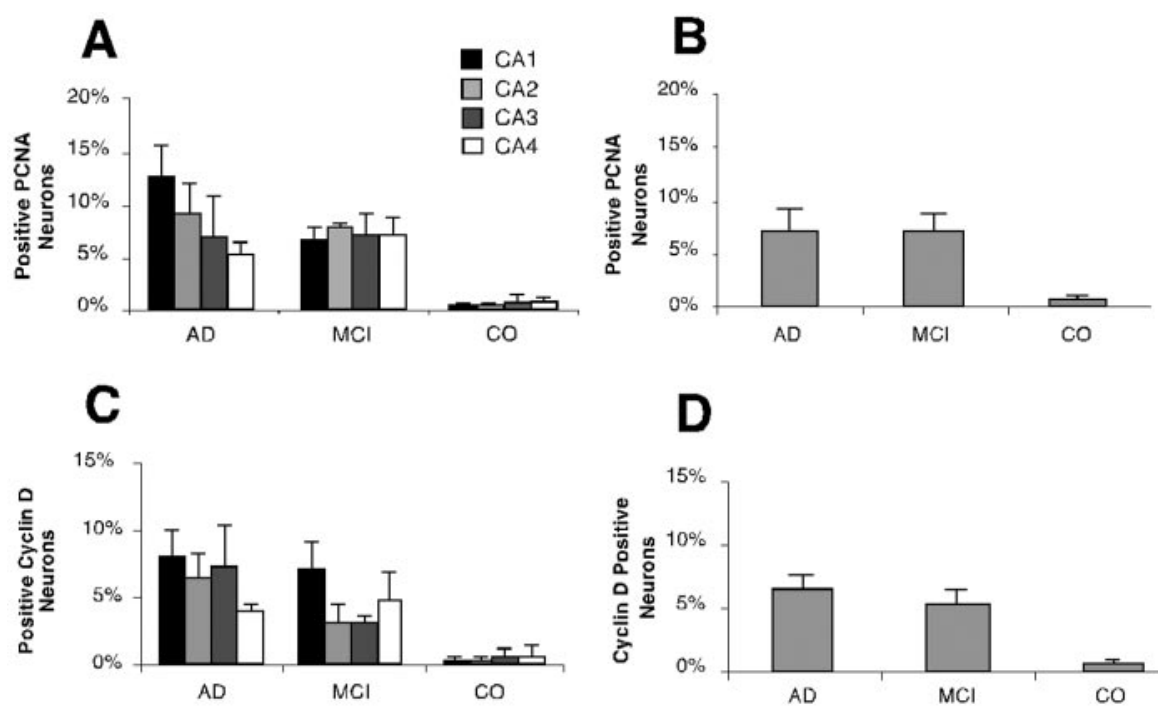

Figure 7. Percentages of immunopositive neurons stained with cell cycle markers in the hippocampus of MCl, AD, and control. Cells were scored for the presence of cell cycle proteins as described in Materials and Methods. Because the anatomical position of the sections scored varied from case to case, all results were expressed as "percent positive" neurons. The results for PCNA $(A, B)$ and cyclin $D(C, D)$ are shown separately. For each case an attempt was made to count percentages in four $C A$ fields separately $(A, C)$. There will be inaccuracies in these estimates as discussed in Results. The percentages of the entire hippocampal pyramidal cell population are also reported $(B, D)$. In $A$ and $C$, the percentage for CA1 is shown in black, CA2 is shown in dark gray, CA3 is shown in light gray, and CA4 is shown in white. Values shown are means of the percentages calculated in each case; the error bars represent $\mathrm{SES}$.

\section{Discussion}

The results presented here document that the involvement of cell cycle processes occurs early in the progression of $\mathrm{AD}$. In every case clinically categorized as MCI, a small but important fraction of neurons in the hippocampal complex is immunopositive for several proteins that should only be present in cells undergoing mitosis. This finding applies to the pyramidal neurons of the hippocampus as well as to cell bodies within the entorhinal cortex and the magnocellular cholinergic neurons of the basal nucleus of Meynert. Counts in the hippocampal region suggest that in both $\mathrm{AD}$ and $\mathrm{MCI}$, the percentage of neurons that are positive for cell cycle markers is between 5 and $10 \%$. These findings have considerable importance because a significant amount of experimental evidence both in vivo (al-Ubaidi et al., 1992; Jacks et al., 1992; Lee et al., 1992) and in vitro (Park et al., 1997, 1998; Wu et al., 2000) has shown that once a CNS neuron leaves the ventricular zone it can never reenter a cell cycle. If it does so, whether by force (al-Ubaidi et al., 1992; Feddersen et al., 1992, 1995) or by natural processes (Herrup and Busser, 1995), it will die rather than divide.

Our analysis of the regional variation in cell cycling in hippocampus should be considered in the context of earlier work on the relative extent of cell loss in the various hippocampal subfields. It is generally considered that the cell loss in the CA1 region is greater than in the other CA fields (West et al., 1994). Although we find no dramatic regional differences in the levels of cell cyclepositive neurons, there is a trend for the CA1 field to have a higher percentage of PCNA-positive neurons in both MCI and AD. The absence of a large difference among the CA fields is noteworthy because it differs from the generally held idea that the disease reveals a different vulnerability among the CA neurons. One explanation of this apparent discrepancy might lie in the fact that the neuronal cell counts referred to in the earlier studies represent an absolute level of cumulative neuron loss, whereas our cell counts reflect the percentage of cells in the process of dying. Thus one factor contributing to the unexpectedly small differences among the fields might be that the rate of cell loss is regionally variable. For example, if the death of CA4 neurons after entrance into the cell cycle were slow while that of CA1 were fast, then one would predict much less cell death in the former region than in the latter. Other factors affecting the comparison of our data with earlier studies might include the possibility that not all neurons are capable of forming NFTs, whereas others may form them at different rates. If this is correct, cell cycle reentry might be activated simultaneously in different parts of the brain, but its progression and subsequent death mechanism might proceed at variable rates. It is interesting in this regard that we found cell cycle markers within the magnocelluar/cholinergic neurons of the nucleus basalis, which are not affected in MCI and early AD (Gilmor et al., 1999). Further studies of this neuronal population as well as others resistant to AD pathology (i.e., basal ganglia, thalamus, and occipital cortex) would lend support to the hypothesis that rate of neuronal loss in response to cell cycle changes is regionally and pathologically variable. At present there is no obvious way to test these ideas, although the analysis of additional cases would be of considerable benefit.

Our finding of large numbers of cell cycle stained neurons in the entorhinal cortex is in agreement with earlier work showing the early involvement of this region in the expression of AD pathology. For example, several studies have shown an early loss of neurons in this region (Gomez-Isla et al., 1996; Kordower et al., 2001), a finding that is consistent with the early appearance of neurofibrillary tangles (Braak and Braak, 1991). By the time the disease progresses to severe $\mathrm{AD}$, previous studies report a 7590\% neuronal loss (Lippa et al., 1992; Fukutani et al., 1995). The material that we have sampled, although less extensive than these earlier studies, is in substantial qualitative agreement.

The present findings suggest that, throughout the course of the disease, neuronal death in $\mathrm{AD}$ has as its root cause an ectopic reentrance into the cell cycle. This is an important finding because it offers a single unified mechanism of cell loss for this highly prevalent dementia and suggests that a single disease process is at work throughout. The probability of an alternative hypothesis, that cell cycle involvement is a peculiarity of the end stage of the disease, is diminished by the present findings. Rather than being a rare but stable event that collects in the brain or an agonal process that occurs only in the final stages of disease, our findings showing that cell cycle proteins are found within neurons of people with MCI suggest that cell cycle-induced death is a central mechanistic feature of the disease. A further implication of this line of reasoning is that cell cycle antigens are perhaps one of the best markers for dying neurons at all disease stages.

Individuals with a diagnosis of MCI have minor but significant symptoms of the early stages of $\mathrm{AD}$. Although some researchers would be hesitant to portray MCI as the obligate first stage of $\mathrm{AD}$, the fact is that a relatively high percentage of these individuals will become progressively impaired and will eventually deteriorate to the point where a diagnosis of $\mathrm{AD}$ is appropriate (Petersen, 2000a,b; Bennett et al., 2002). For the purposes of 
our study, it is assumed that the cases obtained from individuals classified as MCI are at the very least highly enriched for a prodromal stage of AD. However, we recognize that many would argue that, had they lived, up to $30 \%$ of our cases might have gone on to other neurological conditions (Petersen, 2000b). This raises an important consideration. Because we used clinical-behavioral criteria to group our subjects, a priori one might have expected to find on the order of $30 \%$ of our MCI cases to be without significant cell cycle involvement. That 10 of 10 of our MCI cases were cell cycle positive (range, $2.2-15.4 \%$ of cells) suggests that nearly all forms of dementia that evolve from MCI are accompanied by cell cycle-triggered cellular dysfunction. This conclusion is implicit in earlier studies (Mufson et al., 2000, 2002); an alternative explanation, that all MCI goes on to $\mathrm{AD}$, is contradicted by the literature on the topic [see as only one example Meyer et al. (2002)]. We are currently pursuing these predictions by examining later stages of various non-Alzheimer dementias.

We find that the percentages of stained neurons are nearly equivalent in both $\mathrm{MCI}$ and mild to moderate $\mathrm{AD}$. As we have previously pointed out, the relatively high percentage of positive neurons that we observe $(5-10 \%)$ is incompatible with a cell death process that is rapid and apoptosis-like. If cell death were to take $12 \mathrm{hr}$ (from cell cycle entrance to cell body loss) as it does in vitro (S. M. Cicero, K. Herrup, unpublished observations) and in developing mouse brain in vivo (Lee et al., 1994; Busser et al., $1998)$, then $\sim 1$ of 7300 neurons $(0.01 \%)$ would be in the death process at any one moment if we assume a $\sim 10$ year disease process. We find hundreds of times that number, suggesting that the cells are "stuck" for many months (possibly up to 1 year) in a cycle they cannot complete. These observations indicate that in both early and latter stages of $\mathrm{AD}$, cell loss will continue even if disease progression is arrested completely. This has implications for the conduct of Alzheimer clinical trials in general and drug trials in particular. An effective treatment might stop the disease process but would do nothing to alleviate the nuclear-cytoplasmic "imbalance" in the $5-10 \%$ of the neurons that we have identified as cell cycle positive. These cells are still fated to die. Thus in the period between therapy initiation and final stabilization, neurons would continue to be lost, and, it may be presumed, cognition would continue to decline. The prediction, therefore, is that clinical trials that are only weeks in duration could significantly underestimate the efficacy of a proposed new treatment. An obvious corollary to this concept is that there is a significant advantage to detecting and treating Alzheimer's disease at the earliest possible stage.

\section{References}

al-Ubaidi MR, Hollyfield JG, Overbeek PA, Baehr W (1992) Photoreceptor degeneration induced by the expression of simian virus 40 large tumor antigen in the retina of transgenic mice. Proc Natl Acad Sci USA 89:1194-1198.

Arendt T, Rodel L, Gartner U, Holzer M (1996) Expression of the cyclindependent kinase inhibitor p16 in Alzheimer's disease. NeuroReport 7:3047-3049.

Arendt T, Holzer M, Gartner U (1998) Neuronal expression of cyclin dependent kinase inhibitors of the INK4 family in Alzheimer's disease. J Neural Transm 105:949-960.

Arnold S, Hyman B, J F (1991) The topographical and neuroanatomical distribution of neurofibrillary tangles and neuritic plaques in cerebral cortex of patients with Alzheimer's disease. Cereb Cortex 1:103-116.

Baldin V, Lukas J, Marcote MJ, Pagano M, Draetta G (1993) Cyclin D1 is a nuclear protein required for cell cycle progression in G1. Genes Dev 7:812-821.

Baumann K, Mandelkow EM, Biernat J, Piwnica-Worms H, Mandelkow E (1993) Abnormal Alzheimer-like phosphorylation of tau-protein by cyclin-dependent kinases cdk2 and cdk5. FEBS Lett 336:417-424.
Bennett DA, Wilson RS, Schneider JA, Evans DA, Beckett LA, Aggarwal NT, Barnes LL, Fox JH, Bach J (2002) Natural history of mild cognitive impairment in older persons. Neurology 59:198-205.

Braak H, Braak E (1991) Neuropathological staging of Alzheimer-related changes. Acta Neuropathol 82:239-259.

Busser J, Geldmacher DS, Herrup K (1998) Ectopic cell cycle proteins predict the sites of neuronal cell death in Alzheimer's disease brain. J Neurosci 18:2801-2807.

Feddersen RM, Ehlenfeldt R, Yunis WS, Clark HB, Orr HT (1992) Disrupted cerebellar cortical development and progressive degeneration of Purkinje cells in SV40 T antigen transgenic mice. Neuron 9:955-966.

Feddersen RM, Clark HB, Yunis WS, Orr HT (1995) In vivo viability of postmitotic Purkinje neurons requires $\mathrm{pRb}$ family member function. Mol Cell Neurosci 6:153-167.

Fukutani Y, Kobayashi K, Nakamura I (1995) Neurons, intracellular and extracellular neurofibrillary tangles in subdivisions of the hippocampal cortex in normal ageing and Alzheimer's disease. Neurosci Lett 200:57-60.

Gilmor ML, Erickson JD, Varoqui H, Hersh LB, Bennett DA, Cochran EJ, Mufson EJ, Levey AI (1999) Preservation of nucleus basalis neurons containing choline acetyltransferase and the vesicular acetylcholine transporter in the elderly with mild cognitive impairment and early Alzheimer's disease. J Comp Neurol 411:693-704.

Gomez-Isla T, Price JL, McKeel Jr DW, Morris JC, Growdon JH, Hyman BT (1996) Profound loss of layer II entorhinal cortex neurons occurs in very mild Alzheimer's disease. J Neurosci 16:4491-4500.

Guillery RW, Herrup K (1997) Quantification without pontification: choosing a method for counting objects in sectioned tissues. J Comp Neurol 386:2-7.

Herrup K, Busser JC (1995) The induction of multiple cell cycle events precedes target-related neuronal death. Development 121:2385-2395.

Hoozemans JJ, Bruckner MK, Rozemuller AJ, Veerhuis R, Eikelenboom P, Arendt T (2002) Cyclin D1 and cyclin E are co-localized with cyclooxygenase 2 (COX-2) in pyramidal neurons in Alzheimer disease temporal cortex. J Neuropathol Exp Neurol 61:678-688.

Hyman B, Van Hoesen G, Damasio A, Barnes C (1984) Alzheimer's disease: cell specific pathology isolates the hippocampal formation in Alzheimer's disease. Science 225:1168-1170.

Hyman B, Van Hoesen G, Kromer L, Damasio A (1986) Perforant pathway changes and the memory impairment of Alzheimer's disease. Ann Neurol 20:472-481.

Jacks T, Fazeli A, Schmitt E, Bronson R, Goodell M, Weinberg R (1992) Effects of an Rb mutation in the mouse. Nature 359:295-300.

Kordower JH, Chu Y, Stebbins GT, DeKosky ST, Cochran EJ, Bennett D, Mufson EJ (2001) Loss and atrophy of layer II entorhinal cortex neurons in elderly people with mild cognitive impairment. Ann Neurol 49:202-213.

Lee EY-HP, Chang C-Y, Hu N, Wang Y-CJ, Lai C-C, Herrup K, Lee W-H, Bradley A (1992) Mice deficient for Rb are nonviable and show defects in neurogenesis and haematopoiesis. Nature 359:288-294.

Lee EY-HP, Hu N, Yuan S-SF, Cox LA, Bradley A, Lee W-H, Herrup K (1994) Dual roles of the RB protein in cell cycle regulation and neuron differentiation. Genes Dev 8:2008-2021.

Lew J, Wang JH (1995) Neuronal cdc2-like kinase. Trends Biochem Sci 20:33-37.

Lippa C, Hamos J, Pulaski-Salo D (1992) Alzheimer's disease and aging: effects on perforant pathway perikarya and synapses. Neurobiol Aging 13:405-411.

McShea A, Harris PL, Webster KR, Wahl AF, Smith MA (1997) Abnormal expression of the cell cycle regulators P16 and CDK4 in Alzheimer's disease. Am J Pathol 150:1933-1939.

Meyer JS, Xu G, Thornby J, Chowdhury MH, Quach M (2002) Is mild cognitive impairment prodromal for vascular dementia like Alzheimer's disease? Stroke 33:1981-1985.

Mitchell TW, Mufson EJ, Schneider JA, Cochran EJ, Nissanov J, Han LY, Bienias JL, Lee VM, Trojanowski JQ, Bennett DA, Arnold SE (2002) Parahippocampal tau pathology in healthy aging, mild cognitive impairment, and early Alzheimer's disease. Ann Neurol 51:182-189.

Morris JC, Storandt M, Miller JP, McKeel DW, Price JL, Rubin EH, Berg L (2001) Mild cognitive impairment represents early-stage Alzheimer disease. Arch Neurol 58:397-405.

Mufson EJ, Chen EY, Cochran EJ, Beckett LA, Bennett DA, Kordower JH 
(1999) Entorhinal cortex beta-amyloid load in individuals with mild cognitive impairment. Exp Neurol 158:469-490.

Mufson EJ, Ma SY, Cochran EJ, Bennett DA, Beckett LA, Jaffar S, Saragovi HU, Kordower JH (2000) Loss of nucleus basalis neurons containing trkA immunoreactivity in individuals with mild cognitive impairment and early Alzheimer's disease. J Comp Neurol 427:19-30.

Mufson EJ, Ma SY, Dills J, Cochran EJ, Leurgans S, Wuu J, Bennett DA, Jaffar S, Gilmor ML, Levey AI, Kordower JH (2002) Loss of basal forebrain P75(NTR) immunoreactivity in subjects with mild cognitive impairment and Alzheimer's disease. J Comp Neurol 443:136-153.

Nagy Z, Esiri M, Cato A, Smith A (1997) Cell cycle markers in the hippocampus in Alzheimer's disease. Acta Neuropathol (Berl) 94:6-15.

Park DS, Morris EJ, Greene LA, Geller HM (1997) G1/S cell cycle blockers and inhibitors of cyclin-dependent kinases suppress camptothecininduced neuronal apoptosis. J Neurosci 17:1256-1270.

Park DS, Morris EJ, Padmanabhan J, Shelanski ML, Geller HM, Greene LA (1998) Cyclin-dependent kinases participate in death of neurons evoked by DNA-damaging agents. J Cell Biol 143:457-467.

Petersen RC (2000a) Aging, mild cognitive impairment, and Alzheimer's disease. Neurol Clin 18:789-806.

Petersen RC (2000b) Mild cognitive impairment: transition between aging and Alzheimer's disease. Neurologia 15:93-101.

Price J, Davis P, Morris J, White D (1991) The distribution of tangles, plaques and related immunohistochemical markers in healthy aging and Alzheimer's disease. Neurobiol Aging 12:295-312.
Prosperi E (1997) Multiple roles of the proliferating cell nuclear antigen: DNA replication, repair and cell cycle control. Prog Cell Cycle Res 3:193-210.

Rossler M, Zarski R, Bohl J, Ohm TG (2002) Stage-dependent and sectorspecific neuronal loss in hippocampus during Alzheimer's disease. Acta Neuropathol (Berl) 103:363-369.

Vincent I, Rosado M, Davies P (1996) Mitotic mechanisms in Alzheimer's disease? J Cell Biol 132:413-425.

Vincent I, Jicha G, Rosado M, Dickson D (1997) Aberrant expression of mitotic cdc2/cyclin B1 kinase in degenerating neurons of Alzheimer's disease brain. J Neurosci 17:3588-3598.

West M, Coleman P, Flood D, JC T (1994) Differences in the pattern of hippocampal neuronal loss in normal ageing and Alzheimer's disease. Lancet 344:769-772.

Whitehouse P, Price D, Struble R, Clark A, Coyle J, DeLong M (1982) Alzheimer's disease and senile dementia: loss of neurons in the basal forebrain. Science 215:1237-1239.

Wu Q, Combs C, Cannady SB, Geldmacher DS, Herrup K (2000) Betaamyloid activated microglia induce cell cycling and cell death in cultured cortical neurons. Neurobiol Aging 21:797-806.

Yang Y, Geldmacher DS, Herrup K (2001) DNA replication precedes neuronal cell death in Alzheimer's disease. J Neurosci 21:2661-2668.

Zweig R, Ross C, Hedreen J, Steele C, Cardillo J, Whitehouse P, Folstein M, Price D (1988) The neuropathology of aminergic nuclei in Alzheimer's disease. Ann Neurol 24:233-242. 